\title{
DRUG RESISTANT TUBERCULOSIS THAT ARE DIAGNOSED IN PRIMARY CASES AND RETREATMENT CASES IN RIVERS STATE
}

\author{
Victor Oris-Onyiri $^{{ }^{*}}$, Precious Ilueme ${ }^{1}$, Helen Nyeche ${ }^{1}$, Tonye Tamuno-Adoki ${ }^{1}$, and Elizabeth \\ Onyiri $^{1}$ \\ ${ }^{1}$ Rivers State Ministry of Health, \\ Port Harcourt, Nigeria
}

\begin{abstract}
Drug resistant tuberculosis studies in Rivers State, an oil-rich area in Nigeria. The National Tuberculosis, Leprosy and Buruli Ulcer program at the state level started around 2009 and drug-resistant tuberculosis started receiving data from the local government areas of the state. The data generated for this research is from the state ministry of health in the NTLB. This study is carried out to assess the trend of drug-resistant tuberculosis in the state, a total of 250 patients were used for this research with male $147(58.8 \%)$ and female $103(41.2 \%)$. The retreatment cases were 190(76\%) while primarily diagnosed or new cases were $60(24 \%)$. SPSS version 24 was used to analyze the data with t-test and linear regression used as statistical tools. From a linear regression test, the trend of drug-resistant tuberculosis in the state was increasing until 2016 where it has its highest occurrence and is gradually declining. A test of significance showed that females have a better outcome, less in HIV co-infection compared to males of the same age groups of 15-44 that had the highest number. Retreatment cases of drug-resistant tuberculosis are not favorable when compared to the new cases, the incidence of death, loss to follow up are more among the males in retreatment of drug-resistant tuberculosis. All these findings may be associated with some level of factors this research tried to do but was limited to a certain stage.
\end{abstract}

Keywords: Drug resistant tuberculosis, Retreatment cases, prevalence, HIV, Trend, New cases and Rivers.

\section{INTRODUCTION}

Drug resistance tuberculosis by WHO is any resistant tuberculosis with clinical relevance, including multi drug-resistant (MDRTB), poly drug-resistant (PDR-TB) and extensively drug-resistant tuberculosis (XDR-TB). Evaluation differs from research in that the results may be setting specific and the methodology is not aimed at generability of the results. Evaluation, nevertheless, does not provide useful information, in particular if the evaluation process can be replicated in other settings. Once established, rigorous recording and reporting systems of DR-TB programs can be a rich source of evaluation data, and additionally, provide a platform for epidemiological or operational research.

\subsection{OBJECTIVES}

The objectives of the study is

1. To determine the prevalence of DR-TB in Rivers State between 2013-2018.

2. To determine new treatment and retreatment cases in Rivers State.

3. To assess the level of risk factors in drug resistance using HIV prevalence.

4. To assess incidence and mortality of DR-TB in Rivers State.

Patients with retreatment tuberculosis represent those who have been treated previously for one month or more with anti-TB drugs and who have been diagnosed once again with the disease. These patients may include relapses, treatment after failure, or loss to follow-up on a first line treatment regimen. The numbers of patients who are retreatment are large in number. Patients with new 
cases of tuberculosis refer to any diagnosed TB patient who has never had treatment for TB, or who has taken anti-TB drugs for less than 4 weeks. This classification of new patient is irrespective of site of the disease or whether patient was bacteriologically or clinically diagnosed.

Retreatment cases of TB have been known to have a higher risk of drug resistance compared with new cases. So, all TB patients irrespective of the category is advised to screen for HIV co-infection; NTPs have been advised since 2010 by WHO to systematically test at diagnosis all retreatment TB patients for culture but currently is been diagnosed with molecular. The National Guideline of Tuberculosis Control and Management is been used in Rivers state to diagnose with GeneXpert in order to detect resistance to rifampicin which is usually synonymous with multidrug resistance.

In Rivers State, a South-south region in Nigeria has no actual record on incident of TB cases, but from the monitoring and evaluation retreatment cases might show to be higher. But currently there is no previous studies conducted in Rivers State or in south-south Nigeria to show incidence and new and retreatment cases.

\subsection{MATERIALS AND METHODS}

\subsection{Study Design}

This study was a retrospective cohort study using data generated in a yearly and quarterly line listing.

\subsection{General setting and study sites}

Rivers state is oil producing in Nigeria with a population of about 7,000,000 in the state. The state shares borders with Bayelsa, Akwa-Ibom, Delta, Imo and Anambra state.

\subsection{NATIONAL TUBERCULOSIS MANAGEMENT AND CONTROL GUILDLINES}

Rivers state ministry of health follows the WHO DOTS strategy for diagnosis and treatment of patients.

\subsection{Study Population}

All cases of patients in line listing between May 2014 and September 2018 were included in the study.

\subsection{Analysis and Statistics}

Data from Microsoft excel sheet line listing were entered into an electronic spreadsheet file using SPSS Software and analyzed using this software (SPSS version 24).

\subsection{RESULTS}

Between May 2014 to September 2018, 274 DR-TB patients were diagnosed. 197 retreatment DR-TB Patients were treated in Rivers state on the basis of a positive result using GeneXpert which is molecular testing. 


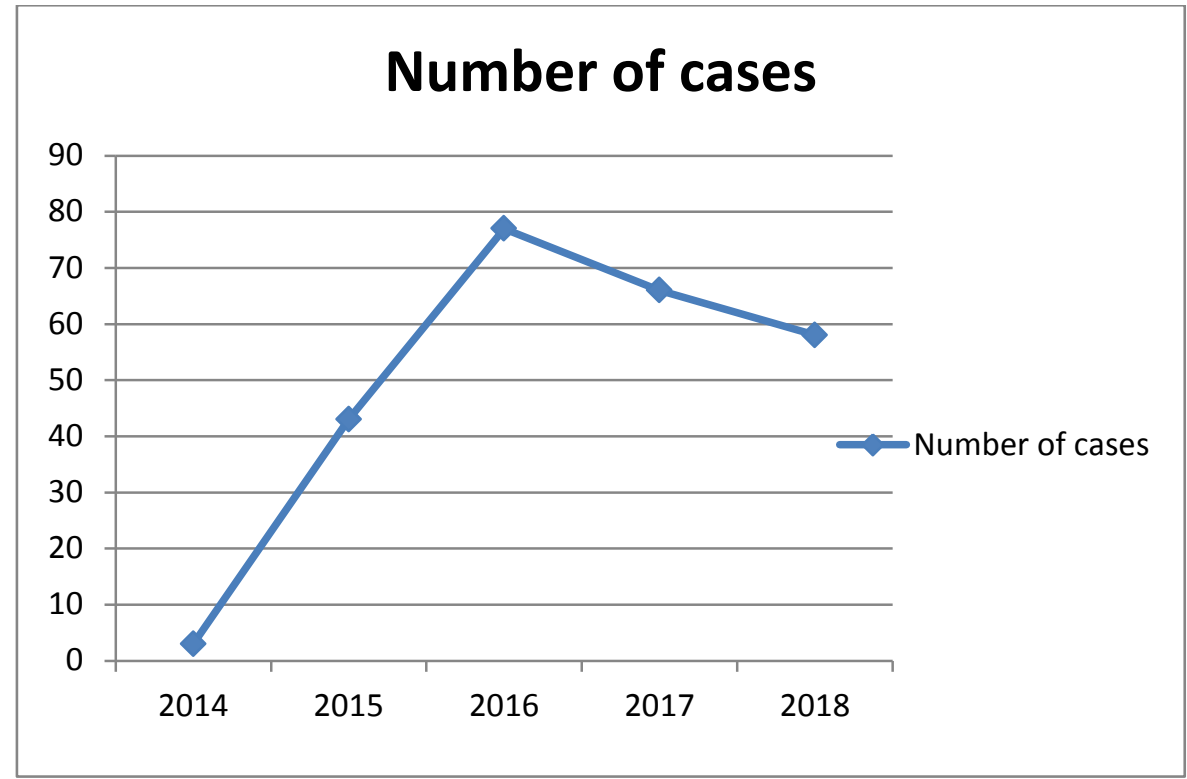

Figure 1 Trends of Drug-Resistant Tuberculosis from 2014 to 2018

Table 1: Prevalence of DR-TB Cases in Rivers State.

\begin{tabular}{lllll}
\hline Age groups & Female & Male & New cases & Retreatment cases \\
\hline $0-4$ & 0 & 0 & 0 & 0 \\
$5-14$ & 2 & 2 & 1 & 5 \\
$15-24$ & 15 & 9 & 10 & 14 \\
$25-34$ & 28 & 47 & 22 & 52 \\
$35-44$ & 29 & 46 & 21 & 51 \\
$45-54$ & 17 & 30 & 17 & 27 \\
$55-64$ & 6 & 9 & 4 & 9 \\
$>65$ & 3 & 1 & 2 & 4 \\
\hline
\end{tabular}

Table 4.2: Proportion of New Tuberculosis cases with respect to age, sex and HIV status

\begin{tabular}{llllll}
\hline Age Group & Males & Females & HIV Negative & HIV Positive & Total \\
\hline $0-4$ & 1 & - & 1 & - & 1 \\
$5-14$ & - & 1 & 1 & - & 1 \\
$15-24$ & 3 & 6 & 8 & 1 & 9 \\
$25-34$ & 14 & 9 & 14 & 9 & 23 \\
$35-44$ & 14 & 14 & 14 & 14 & 28 \\
$45-54$ & 13 & 9 & 10 & 12 & 22 \\
$55-64$ & 5 & - & 4 & 1 & 5 \\
$\geq 65$ & - & - & - & - & - \\
Total & 50 & 39 & 52 & 37 & 89 \\
\hline
\end{tabular}


International Journal of Advances in Scientific Research and Engineering (ijasre), Vol 5 (6), June-2019

Table 4.3: HIV co-infection with Sex comparison

\begin{tabular}{llllll}
\hline Age Group & Male Neg. & Male Pos. & Female Neg. & Female Pos. & Total \\
\hline $0-4$ & 1 & - & - & - & 1 \\
$5-14$ & - & - & 1 & - & 1 \\
$15-24$ & 3 & - & 5 & 1 & 9 \\
$25-34$ & 10 & 5 & 5 & 3 & 23 \\
$35-44$ & 9 & 5 & 6 & 8 & 28 \\
$45-54$ & 10 & 3 & 5 & 4 & 22 \\
$55-64$ & 4 & 1 & - & - & 5 \\
$\geq 65$ & - & - & - & - & - \\
Total & 37 & 14 & 22 & 16 & 89 \\
\hline
\end{tabular}

Retreatment TB patients refers to any diagnosed TB patient who have received four weeks or more of anti-TB drugs in the past. They may have expert, smear, culture positive/negative and are further classified by the outcomes of their most recent course of treatment as follows; relapse patient, treatment after failure patients, treatment after loss to follow-up, other previously treated patients and patients with unknown TB treatment history. This study classified the last two categories as others as stated in the table below.

Table 4.4: Distribution of Retreatment Tuberculosis by type and sex

\begin{tabular}{lcccc}
\hline Type of patient & Male (\%) & Female (\%) & T-test & P-value \\
\hline Relapse & 69 & 42 & 0.078 & 0.46 \\
Failure & 13 & 15 & 1.42 & 0.065 \\
$\begin{array}{l}\text { Treatment after loss to } \\
\text { follow-up }\end{array}$ & 30 & 21 & 4.10 & 0.00001 \\
& & & & \\
Other & 10 & 5 & 3.42 & 0.00002 \\
Total & 122 & 83 & & \\
\hline
\end{tabular}


International Journal of Advances in Scientific Research and Engineering (ijasre), Vol 5 (6), June-2019

Table 4.5: Different favourable and unfavourable outcomes in retreatment TB cases by sex and Age.

\begin{tabular}{lcccc}
\hline Outcome & Male $(\%)$ & Female $(\%)$ & T test & P-value \\
\hline Favorable & & & & \\
Cure & 8.25 & 15.5 & 11.1 & 0.024 \\
Treatment & 20.2 & 28.7 & 10.41 & 0.008 \\
Complete & 9.2 & 16.5 & 9.70 & 0.01 \\
Unfavourable & & & & \\
Failure & 18.3 & 14 & 9.056 & 0.014 \\
Default & 14.6 & 12.4 & 8.35 & 0.02 \\
Death & 29.4 & 12.4 & 7.64 & 0.03 \\
Total & 109 & 97 & & \\
\hline
\end{tabular}

\section{DISCUSSIONS}

Prevalence of TB cases was done and HIV Status of these patients was as well analyzed. The prevalence was $33.94 \%$ for males between the age group of 25-44 in Rivers State and 20.8\% for females between the age group of 25-44. These same age groups shows to have prevalence of new and retreatment cases of tuberculosis in Rivers state as well. The study also showed that HIV Prevalence among retreatment patients were $72 \%$ compared to new cases.

Tuberculosis, especially drug resistant tuberculosis in this retrospective study increased significantly up until 2016 where it got to the peak and decline is on a gradual decrease as shown in the fig. 1. Although this does not seem to agree with the research in Jigawa(Nigeria) that recorded increase in tuberculosis though between 2009 to 2014 as the years grow showing how prevalent it is in the area(Isa et.al , 2012).

Relapse patients are on increase with level of significance being statistical $69 \%$ for males and $42 \%$ for the females with more men compared to women although more men where line listed from the data generated, the loss of follow-up was not statistically significant in terms of retreatment cases of the drug resistant tuberculosis in Rivers state, it could be that those in field are doing well in this or any other factor that was not considered in the research. The level of significance with the outcomes has been more unfavourable with high incidence of death. Although HIV co-infection could be reason for the death or lack of drugs and access to quality medical care could be some reasons that this research did not go to find out.

\section{CONCLUSION}

Studies in tuberculosis generally in some parts of Nigeria suggests that prevalence of tuberculosis is more prevalent among men than women, this study tends to agree with those studies especially considering the proportion and percentage of men to women even in terms of favourable outcome. Retreatment of drug resistant tuberculosis has not really shown to be positive from the findings of this research, although new cases have shown to be currently. 


\section{ACKNOWLEDGEMENT}

We are grateful to Mrs. Nyeche the DR-TB focal person in the state and Mr. Tonye the M\&E officer of the State tuberculosis programme. To Dr. Golden Owhonda the Director of Public health and disease control in Rivers State Ministry of Health we say a big thank you.

\section{REFERENCES}

1. Christopher, C; Emeka, K and Vivien V (2000). The pattern of presentation and prevalence of Tuberculosis in HIVSeropositive patients seen in Benin city, Nigeria. International Scholarly Research Network,

2. Isa, A and Evren, H (2015). Statistical Analysis of Tuberculosis in Jigawa State, NorthWestern Nigeria. Malays J. Med. Biol, 2(2); pp 237-239.

3. National Tuberculosis, Leprosy And Buruli Ulcer Management and Control Guidelines (2015). $6^{\text {th }}$ ed.; pp 74-78.

4. Nakanwagi-Mukwaya, A; Reid A; Fujiwara, P; Mugabe, F; Kosgei, R; Taylor-Smith, K; Kizito, W; Joloba, M (2013). Characteristics and treatment outcomes of tuberculosis retreatment cases in three regional hospitals in Uganda. Public Health Action 3(2); pp149.

5. World Health Organization (2016). Research Agenda on Drug Resistant Tuberculosis with a focus on scaling up programmes.

6. World Health Organization (2014). Understanding and using tuberculosis data. 